\title{
Indications, Yield and Outcome of Colonoscopy: A 7-Year Retrospective Study in a Resource-Limited Setting
}

\author{
Gabin Ulrich Kenfack ${ }^{1,2 *}$, Servais Albert Fiacre Bagnaka Eloumou ${ }^{3,4}$, Winnie Tatiana Bekolo Nga ${ }^{3,4}$, \\ Guy Sadeu Wafeu ${ }^{1}$, Paul Nkemtendong Tolefac ${ }^{1}$, Agnès Malongue ${ }^{4}$, Mathurin Pierre Kowo ${ }^{1}$, \\ Christian Tzeuton ${ }^{3,5}$, Firmin Ankouane Andoulo1, Oudou Njoya1,2, Henry Namme Luma1,3, \\ Dominique Noah Noah ${ }^{3,6}$
}

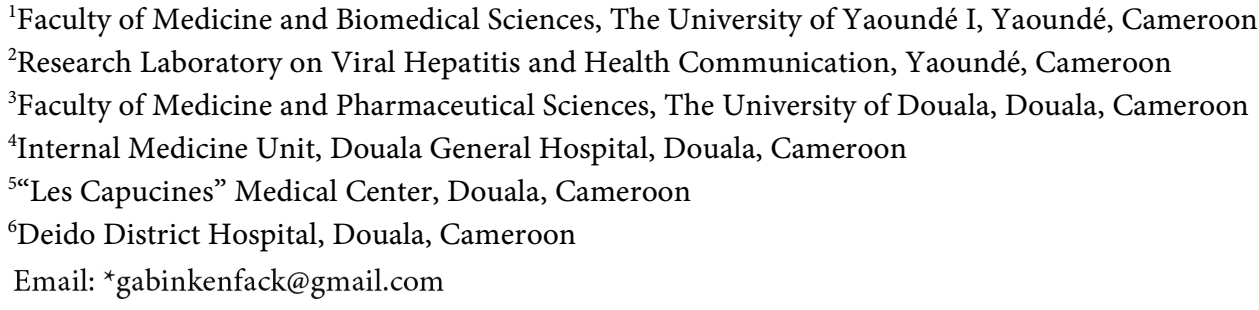

How to cite this paper: Kenfack, G.U. Eloumou, S.A.F.B., Nga, W.T.B., Wafeu, G.S., Tolefac, P.N., Malongue, A., Kowo, M.P., Tzeuton, C., Andoulo, F.A., Njoya, O., Luma, H.N. and Noah, D.N. (2019) Indications, Yield and Outcome of Colonoscopy: A 7-Year Retrospective Study in a Resource-Limited Setting. Open Journal of Gastroenterology, 9, 49-58. https://doi.org/10.4236/ojgas.2019.93008

Received: January 11, 2019

Accepted: March 27, 2019

Published: March 30, 2019

Copyright $\odot 2019$ by author(s) and Scientific Research Publishing Inc. This work is licensed under the Creative Commons Attribution International License (CC BY 4.0).

http://creativecommons.org/licenses/by/4.0/

\section{(c) (i) Open Access}

\begin{abstract}
Background and Aims: Diagnostic colonoscopy allows exploration of the colonic mucosa. Indications are multiple. The purpose of this work was to describe the indications and to report the lesions observed during colonoscopy at the General Hospital of Douala. Methods: This was a cross-sectional study with retrospective data collection over a period of 7 years (January 1 , 2010 to January 31, 2017). The data collected from the reports were socio-demographic characteristics, indications and lesions observed at colonoscopy. Binary logistic regression allowed us to identify the independent risk factors associated with the presence of tumors and polyps. Results: We included 719 exams. The main indications were rectorrhagia (29.5\%), abdominal pain (25.9\%) and constipation (17.8\%). A colonic lesion was found in $60.1 \%$ of cases. A colorectal tumor accounted for $10.3 \%$ of cases. Factors independently associated with colonic tumor were complete colonoscopy (aOR: $0.16795 \%$ CI [0.096 - 0.289], $\mathrm{p}<0.001$ ), presence of abdominal or rectal mass (aOR: 13.390 95\% CI) [5.684 - 31.544], p < 0.001) and weight loss (aOR: 5.143, 95\% CI [2.450 - 10.797], $\mathrm{p}<0.001)$. Conclusion: The presence of weight loss, abdominal or rectal mass should motivate the realization of a complete colonoscopy in search of a colorectal tumor. The most observed lesions remain hemorrhoids, polyps and diverticulosis of the colon.
\end{abstract}




\section{Keywords}

Colonoscopy, Indications, Colorectal Tumor, Limited Resources, Cameroon

\section{Introduction}

The incidence of organic colonic disease is increasing in sub-Saharan Africa [1]. Colonoscopy allows visualization of the entire colonic mucosa [2]. Over time, its practice is more and more necessary and improvements are made to increase its profitability [3]. It is the case of narrow band imaging, which is used in combination with magnesium-enhanced endoscopy to better define precancerous colonic lesions [4] [5]. Thus, colonoscopy is the reference examination of colon exploration for the diagnosis, detection and surveillance of the main colon diseases [6]. It is also an invasive and expensive examination [7]. It is therefore important to determine, among its indications, those which lead to the most frequent diagnosis of neoplastic lesions [8]. Several studies have evaluated the proportion of colonoscopy reporting abnormalities in a given population (cost-effectiveness). In Cameroon, the yield is 51.3\% [9] and reaches 71.9\% in Sudan [10]. The indications for colonoscopy are varied. These include rectorrhagia, abdominal pain, transit changes, weight loss and many other indications. The major advantage of colonoscopy is the ability to perform diagnostic procedures such as sampling. Worldwide, gastrointestinal hemorrhage is the main indication for colonoscopy [1] [9]-[14]. In Cameroon, the main indications for colonoscopy are rectorrhagia (30.9\%), abdominal pain (29.4\%), chronic diarrhea (11.8\%), chronic constipation (8.7\%) [9]. However, all these indications do not always lead to the detection of digestive lesions. Colorectal cancer being the most feared lesion especially found in the subjects of more than 50 years [15]. In view of the risk incurred by patients, the cost of colonoscopy and increasing demand, it seems necessary to limit the indications for colonoscopy. In Africa and Cameroon in particular, colonoscopy is increasingly practiced [1] [9] [13] [16] [17]. Our objective was therefore to evaluate the yield of colonoscopy in lower digestive pathology by describing the indications and outcome in the endoscopy unit of Douala General Hospital.

\section{Methods}

1) Study design, study area and setting

We conducted a cross-sectional study over a period of 7 years, from January 1 , 2010 to January 31, 2017 at the digestive endoscopy unit of Douala General Hospital, a first-class health facility in the health pyramid. It is also a university hospital and has a capacity of 320 beds. The hospital has amongst other units an endoscopy exploratory unit, a gastroenterology outpatient consultation unit and an internal medicine service for hospitalization. Four senior gastroenterologists performed explorations in this unit with a Fujinon EPX-2200 video endoscope 
processor. Endoscopic examinations were performed by a video colonoscope Fujinon EC-201 WL. The disinfection procedure was performed manually according to the protocol of the French digestive endoscopy society [18]. Sedation was done with $10 \mathrm{mg}$ of diazepam diluted in eight milliliters of saline and administered intravenously.

2) Data collection and analysis

Data was collected from the endoscopy reports. The following data were collected: age, sex, indication and lesions observed at colonoscopy.

All the colonoscopy reviews were included in this study. The yield of a colonoscopy was defined by its ability to highlight a particular lesion. Overall yield was determined by the number of colonoscopies revealing abnormalities compared to normal colonoscopies. It was considered complete any colonoscopy visualizing the colon until the caecum.

Data were analyzed using Statistical Package for Social Sciences 21.0. The results were expressed in numbers and percentages for the qualitative variables, mean and standard deviation for the quantitative variables. The chi-square test or the Fisher exact test was used for associations. The binary logistic regression allowed a multivariate analysis to find the factors independently associated with the significant lesions. Only factors associated with significant lesions in univariate analysis has been included in the logistic regression model to obtain adjusted odds ratio and $\mathrm{p}$ value. The threshold of significance was defined for a value $\mathrm{p}<0.05$.

Ethics and consent: All information collected during this work has been treated confidentially. Data collection was retrospective and informed consent was not required. This study was approved by the institutional ethics committee of Douala General Hospital.

\section{Results}

\subsection{Population}

We included 719 colonoscopy reports. The mean age was $51.9 \pm 15.0$ years, with a range of 5 to 88 years and a sex ratio of 1.3 . Subjects older than 50 years accounted for $61.6 \%$ of the population. Complete colonoscopies were reported in $76.7 \%$ of cases.

\subsection{Indications for Colonoscopy}

They have been grouped into three categories namely screening, monitoring and symptom evaluation. Rectorrhagia was the most common indication of colonoscopy accounting for $30 \%$ of the colonoscopies performed. Table 1 summarizes the indications for colonoscopy.

\subsection{Observed Lesions}

No lesions were found in $40 \%$ of colonoscopies. The three most common lesions were hemorrhoids (17.1\%), diverticulosis (16.4\%) and polyps (11.4\%). The 
presence of colorectal tumor accounted for $10.3 \%$.

The overall yield of the colonoscopy was $60.1 \%$. Table 2 summarizes the lesions observed at colonoscopy.

Factors associated with the presence of colorectal tumors

In univariate analysis the male gender (OR: 0.566, 95\% CI [0.349 - 0.919]), performing a complete colonoscopy (OR: 0.184, 95\% CI [0.111 - 0.302]), weight loss (OR: 3.317, 95\% CI [1.713 - 6.421]) and the presence of an abdominal or rectal mass (OR: 8.537, 95\% CI [4.011 - 18.170]) were significantly associated with the presence of a colorectal tumor. In binary logistic regression, the factors independently associated with the colorectal tumor were complete colonoscopy (adjusted OR: 0.167, 95\% CI [0.096 - 0.289]), colorectal cancer surveillance (adjusted OR: 4.783, 95\% CI [1.536 - 14.893]), weight loss (adjusted OR: 5.143 95\% CI [2.450 - 10.797]) and abdominal or rectal mass (OR adjusted: 13.390 95\% CI [5.684 - 31.544]). Table 3 summarizes the factors associated with the presence of colorectal tumors.

Table 1. Indications for colonoscopy.

\begin{tabular}{|c|c|c|}
\hline Indications & Numbers $(n=719)$ & Percentage (\%) \\
\hline Screening & 16 & 2.2 \\
\hline Positive hemocult & 10 & 1.4 \\
\hline Family history of colorectal cancer & 6 & 0.8 \\
\hline Surveillance & 36 & 5.0 \\
\hline Colorectal cancer surveillance & 21 & 2.9 \\
\hline Polyp monitoring & 8 & 1.1 \\
\hline Surveillance of ulcerative colitis & 7 & 1.0 \\
\hline Symptom evaluation & 661 & 92.7 \\
\hline Rectorrhagia & 210 & 29.5 \\
\hline Abdominal pain & 185 & 25.9 \\
\hline Constipation & 127 & 17.8 \\
\hline Iron deficiency anemia & 58 & 8.1 \\
\hline Weight loss & 56 & 7.9 \\
\hline Diarrhea & 39 & 5.5 \\
\hline Abdominal or rectal mass & 31 & 4.3 \\
\hline Alternating diarrhea constipation & 20 & 2.8 \\
\hline Proctalgia & 20 & 2.8 \\
\hline Melena & 13 & 1.8 \\
\hline Primary cancer foci search & 12 & 1.7 \\
\hline Suspicion of CIBD & 11 & 1.5 \\
\hline Other* & 98 & 13.7 \\
\hline Unspecified & 6 & $<0.1$ \\
\hline
\end{tabular}

*: Abdominal bloating, cervical cancer assessment, functional colopathy, dyspepsia, hemorrhoidal disease, dysenteric syndrome. 
Table 2. Lesions observed at colonoscopy.

\begin{tabular}{ccc}
\hline Observed lesions & Numbers $(\mathbf{n}=\mathbf{7 1 9})$ & Percentage (\%) \\
\hline No lesion & 287 & 39.9 \\
Hemorrhoids & 123 & 17.1 \\
Diverticulosis & 118 & 16.4 \\
Polyp & 82 & 11.4 \\
Colorectal tumor & 74 & 10.3 \\
Colitis & 39 & 5.4 \\
Proctitis & 28 & 3.9 \\
Rectal ulcer & 11 & 1.5 \\
Other & 55 & 7.6 \\
\hline
\end{tabular}

*: colonic angiodysplasia, dolichocolon, spasmodic colopathy, erythema colic, fistula, melanosis colic.

Table 3. Factors associated with the presence of colorectal tumor.

\begin{tabular}{|c|c|c|c|c|c|c|c|}
\hline & $\begin{array}{c}\text { Presence of } \\
\text { colorectal } \\
\text { tumor n (\%) }\end{array}$ & $\begin{array}{c}\text { Absence of } \\
\text { colorectal } \\
\text { tumor n (\%) }\end{array}$ & $\begin{array}{c}\text { Total } \\
\mathbf{n}\end{array}$ & OR (95\% CI) & $\mathrm{p}$-value & $\begin{array}{l}\text { Adjusted OR } \\
(95 \% \mathrm{CI})\end{array}$ & $\begin{array}{l}\text { Adjusted } \\
\text { p-value }\end{array}$ \\
\hline Age $\geq 50$ years & $47(10.9)$ & $385(89.1)$ & 432 & $1.141(0.688-1.891)$ & 0.607 & & \\
\hline Male & $33(8.0)$ & $378(92.0)$ & 411 & $0.566(0.349-0.919)$ & 0.021 & $0.630(0.368-1.080)$ & 0.093 \\
\hline $\begin{array}{l}\text { Complete } \\
\text { colonoscopy }\end{array}$ & $32(5.8)$ & $519(92.4)$ & 551 & $0.184(0.111-0.302)$ & $<0.001$ & $0.167(0.096-0.289)$ & $<0.001$ \\
\hline \multicolumn{8}{|l|}{ Screening } \\
\hline Positive hemocult & $1(10.0)$ & $9(90.0)$ & 10 & $0.959(0.120-7.677)$ & 1.000 & & \\
\hline $\begin{array}{l}\text { Family history } \\
\text { of colorectal cancer }\end{array}$ & $0(0)$ & $6(100)$ & 6 & / & 1.000 & & \\
\hline \multicolumn{8}{|l|}{ Surveillance } \\
\hline $\begin{array}{c}\text { Colorectal } \\
\text { cancer surveillance }\end{array}$ & $5(23.8)$ & $16(76.2)$ & 21 & $2.822(1.003-7.939)$ & 0.057 & $4.783(1.536-14.893)$ & 0.007 \\
\hline Polyp monitoring & $0(0)$ & $8(100)$ & 8 & / & 1.000 & & \\
\hline $\begin{array}{l}\text { Surveillance of } \\
\text { ulcerative colitis }\end{array}$ & $0(0)$ & $7(100.0)$ & 7 & I & 1.000 & & \\
\hline \multicolumn{8}{|l|}{ Symptom evaluation } \\
\hline Rectorrhagia & $25(11.9)$ & $185(88.1)$ & 210 & $1.252(0.751-2.087)$ & 0.393 & & \\
\hline Abdominal pain & $15(8.0)$ & $173(92.0)$ & 188 & $0.685(0.378-1.239)$ & 0.197 & & \\
\hline Constipation & $11(8.7)$ & $116(91.3)$ & 127 & $0.787(0.402-1.540)$ & 0.475 & & \\
\hline Iron deficiency anemia & $5(8.6)$ & $53(91.4)$ & 58 & $0.801(0.310-2.072)$ & 0.639 & & \\
\hline Emaciation & $14(25.0)$ & $42(75.0)$ & 56 & $3.317(1.713-6.421)$ & 0.001 & $5.143(2.450-10.797)$ & $<0.001$ \\
\hline Diarrhea & $6(15.4)$ & $33(84.6)$ & 39 & $1.620(0.655-4.006)$ & 0.280 & & \\
\hline $\begin{array}{l}\text { Abdominal } \\
\text { or rectal mass }\end{array}$ & $14(45.2)$ & $17(54.8)$ & 31 & $8.537(4.011-18.170)$ & $<0.001$ & $13.390(5.684-31.544)$ & $<0.001$ \\
\hline $\begin{array}{c}\text { Alternating } \\
\text { diarrhea constipation }\end{array}$ & $1(5.0)$ & $19(95.0)$ & 20 & $0.447(0.059-3.388)$ & 0.711 & & \\
\hline Proctalgia & $2(10.0)$ & $18(90.0)$ & 20 & $0.958(0.218-4.215)$ & 1.000 & & \\
\hline Melena & $1(7.7)$ & $12(92.3)$ & 13 & $0.716(0.092-5.584)$ & 1.000 & & \\
\hline
\end{tabular}


For polyps, univariate analysis revealed the following significantly associated factors: complete colonoscopy (OR: 2.360, 95\% CI [1.189 - 4.684]), colorectal cancer surveillance (OR: 3.242 95\% CI [1.221 - 8.606]), polyp (OR: 58.800, 95\% CI [7.136 - 484.474]) and ulcerative colitis (OR: 5.953, 95\% CI [1.308 - 27.084]) and diarrhea. In multivariate analysis, the factors independently associated with the presence of polyps were the same as those mentioned above with the exception of diarrhea. Table 4 summarizes the factors associated with the presence of polyps.

\section{Discussion}

The aim of this work was to evaluate the yield of colonoscopy in lower digestive pathology according to indications. We report the results of 719 colonoscopies

Table 4. Factors associated with the presence of polyps.

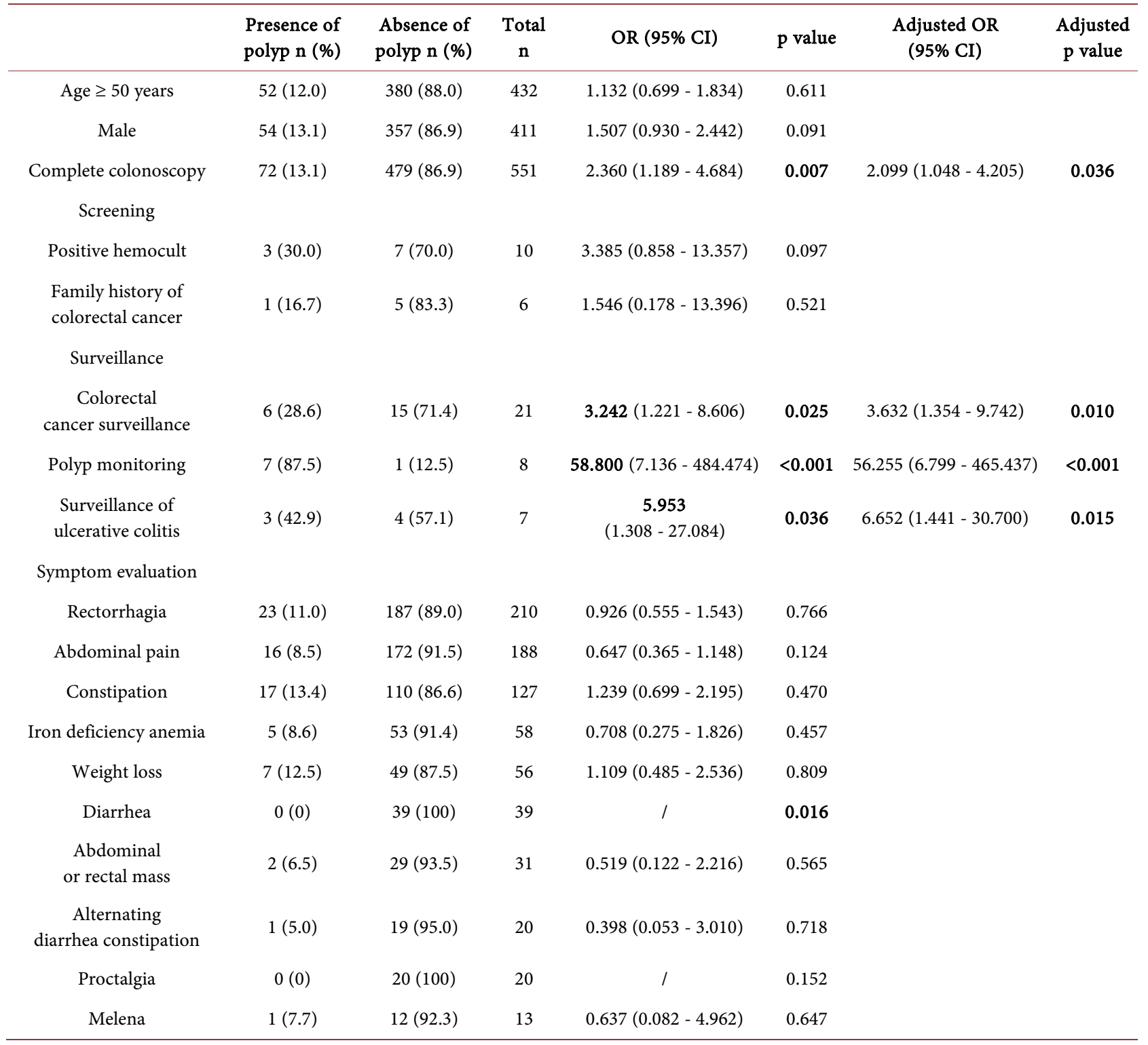


performed in the digestive endoscopy unit of Douala General Hospital in Cameroon. These have made it possible to identify in 432 cases an injury, thus a yield of $60 \%$. In a study conducted in the city of Yaoundé, Ankouane et al. reported a yield of 51.3\% [9]. In Nigeria, it was 79.6\% [13], in Senegal 61.9\% [1]. In Europe, Exbrayat and Kmieciak reported yield of $31.9 \%$ and $43 \%$, respectively [6] [7]. These high rates generally in Africa reflect the fact that colonoscopies are most often performed in subjects already having digestive symptoms. However, the variations observed in the different values would be related to several factors such as the nature of the selected colonoscopies. Colonoscopy indications are varied and found in various proportions depending on the series. In ours, the most common were those related to the evaluation of digestive symptoms accounting for $92.7 \%$ of indications. Ankouane et al. found $90.1 \%$ of indications related to the evaluation of digestive symptoms. This rate is relatively low in the West, so Exbrayat et al. in a series of 1779 colonoscopies reported a proportion of $40 \%$ in this group of indications [7]. Screening in healthy subjects and coverage by insurance coverage in the West makes it possible and justify this disparity. The most common symptoms leading to colonoscopy were rectal bleeding (29.5\%), abdominal pain (25.9\%), constipation (17.8\%), iron deficiency anemia (8.1\%), weight loss (7.9\%). In Yaoundé, it was mainly rectorrhagia (30.9\%), abdominal pain (29.4\%), chronic diarrhea (11.8\%), chronic constipation (8.7\%), iron deficiency anemia (3.0\%) [9]. In Nigeria, Adegboyega et al. found rectorrhagia (34\%), abdominal pain (18.4\%), constipation (10.8\%), diarrhea (8.8\%) and changes in transit (3.6\%) [12]. In America, Lieberman et al. found mainly rectal bleeding (33.6\%) and symptoms suggestive of irritable bowel (23.8\%) [11]. Digestive bleeding at the international level is the main indication of colonoscopy certainly because of the alarming nature of this sign for both the clinician and the patient. Screening was the indication for colonoscopy in $2.2 \%$ of cases in our series with 10 cases $(1.4 \%)$ of positive blood cultures and 6 cases $(0.8 \%)$ of family history of colorectal cancer. Ankouane et al. reported $3.1 \%$ of colonoscopies in this indication with 13 cases (1.4\%) of positive blood cultures [9]. In Senegal, screening for colorectal cancer accounts for $2.65 \%$ of colonoscopy indications [1]. In Europe, Kmieciak reported 22\% colorectal cancer screening and in America, Lieberman reported $35.2 \%$ colorectal cancer screening [6] [11]. In sub-Saharan Africa, there are several barriers to access to care, mainly financial precariousness, the lack of information for subjects at risk of colorectal cancer. In addition, screening is very rare [1] [9]. This inequality also helps to understand the relatively high proportion of subjects over 50 in western series compared to African series [7] [9] [11] [13] [19] because it is established that colorectal cancer occurs mainly after age of 50 [15]. The colonic lesions monitoring accounted for $5 \%$ of our indications. In Yaoundé, it represented 2.9\%, in Europe $22 \%$ and in America 21.7\%.

\section{Conclusion}

The interest of the practice of colonoscopy in sub-Saharan Africa is essentially 
focused on the evaluation of symptoms. It allows in significant proportions to highlight significant colonic lesions, namely colorectal tumors and polyps. The indications independently associated with the colorectal tumor are the completion of a complete colonoscopy, the presence of abdominal mass and weight loss. Therefore, the presence of weight loss, abdominal or rectal mass should motivate the realization of a complete colonoscopy in search of a colorectal tumor. The most observed lesions remain hemorrhoids, polyps and diverticulosis of the colon.

\section{Acknowledgements}

Medical and paramedical staff of digestive endoscopy unit of Douala General Hospital.

\section{Funding}

None.

\section{Contribution of Authors}

Conception of the study: Gabin Ulrich Kenfack and S.A. Eloumou Bagnaka.

Data collection and analysis: Gabin Ulrich Kenfack and Guy Sadeu Wafeu.

Redaction: Gabin Ulrich Kenfack, S.A. Eloumou Bagnaka, Guy Sadeu Wafeu and Paul Nkemtendong Tolefac.

Relecture and supervision: Gabin Ulrich Kenfack, S.A. Eloumou Bagnaka, Winnie Bekolo, Guy Sadeu Wafeu, Paul Nkemtendong Tolefac, A. Malongue, Mathurin Pierre Kowo, C. Tzeuton, F Ankouane Andoulo, Oudou Njoya, H. Luma Namme and D. Noah Noah.

All authors read and approved the final manuscript.

\section{Conflicts of Interest}

Authors declare that they have no competing interests.

\section{References}

[1] Mbengue, M., Dia, D., Diouf, M.L., Bassene, M.L. and Halim, A. (2010) Practice of Colonoscopy in Africa, Analysis of 376 Examinations in Dakar, Senegal. Médecine d Afrique Noire Electronique, 57, 508-512.

[2] JFHOD|SNFGE.org. French Scientific Society of Hepatogastroenterology and Digestive Oncology.

https://www.snfge.org/content/prevalence-des-polypes-coliques-lors-de-la-colo

[3] Puente, D., Cantero, F.X., Llagostera, M., Piñeiro, P., Nieto, R., Saladich, R., et al. (2012) A Cross-Sectional Study of the Appropriateness of Colonoscopy Requests in the Spanish Region of Catalonia. BMJ Open, 2, e002207.

https://doi.org/10.1136/bmjopen-2012-002207

[4] Iwatate, M., Ikumoto, T., Hattori, S., Sano, W., Sano, Y. and Fujimori, T. (2012) NBI and NBI Combined with Magnifying Colonoscopy. Diagnostic and Therapeutic Endoscopy, 2012, Article ID: 173269. https://www.ncbi.nlm.nih.gov/pmc/articles/PMC3523539 
[5] Vişovan, I.I., Tanțău, M., Pascu, O., Ciobanu, L. and Tanțău, A. (2017) The Role of Narrow Band Imaging in Colorectal Polyp Detection. Bosnian Journal of Basic Medical Sciences, 17, 152-158.

[6] Kmieciak Le Corguillé, M., Gaudric, M., Sogni, P., Roche, H., Brézault, C., et al. (2003) Relevance of Colonoscopy Indications in an AP-HP Gastroenterology Department in 2001. Application of Criteria Established by a Panel of European Experts. Gastroentérologie Clinique et Biologique, 27, 213-218.

[7] Exbrayat, C., Garnier, A., Billette de Villemeur, A., Winckel, P., Fournet, J., Bureau Du Colombier, P., Bolla, M. and Jestin, C. (2002) Results of Colocopies According to Their Indications and Consequences for the Detection of Polyps and Colorectal Cancers. Masson, Paris.

[8] Arditi, C., Peytremann-Bridevaux, I., Burnand, B., Eckardt, V.F., Bytzer, P., Agréus, L., et al. (2009) Appropriateness of Colonoscopy in Europe (EPAGE II). Screening for Colorectal Cancer. Endoscopy, 41, 200-208.

https://doi.org/10.1055/s-0028-1119626

[9] Andoulo, F.A., Kowo, M., Nonga, B.N., Djapa, R., Sartre, M.T., Njoya, O., et al. (2016) Indications, Results and Performance of Colonoscopy in an Unfavorable Economic Environment: The Case of Cameroon. Human Health and Disease, 14, $1-6$.

[10] Doumi, E.A., Adam, H.Y. and Hamad, A.M. (2014) Colonoscopy at El Obeid Hospital, Western Sudan. Journal of Medical Sciences, 9, 107-110.

[11] Lieberman, D.A., Holub, J., Eisen, G., Kraemer, D. and Morris, C.D. (2005) Utilization of Colonoscopy in the United States: Results from a National Consortium. Gastrointestinal Endoscopy, 62, 875-883. https://doi.org/10.1016/j.gie.2005.06.037

[12] Akere, A., Oke, T.O. and Otegbayo, J.A. (2016) Colonoscopy at a Tertiary Healthcare Facility in Southwest Nigeria: Spectrum of Indications and Colonic Abnormalities. Annals of African Medicine, 15, 109. https://doi.org/10.4103/1596-3519.188889

[13] Olokoba, A.B., Obateru, O.A., Bojuwoye, M.O., Olatoke, S.A., Bolarinwa, O.A. and Olokoba, L.B. (2013) Indications and Findings at Colonoscopy in Ilorin, Nigeria. Nigerian Medical Journal: Journal of the Nigeria Medical Association, 54, 111-114. https://doi.org/10.4103/0300-1652.110044

[14] Corguillé, M.K.L., Gaudric, M., Sogni, P., Roche, H., Brézault, C., Dieumegard, B., et al. (2008) Relevance of Colonoscopy Indications in an AP-HP Gastroenterology Department in 2001. http://www.em-consulte.com/en/article/99427

[15] Fleshner, P., Slater, G. and Aufses, A.H. (1989) Age and Sex Distribution of Patients with Colorectal Cancer. Diseases of the Colon \& Rectum, 32, 107-111. https://doi.org/10.1007/BF02553821

[16] Ndjitiyap Ndam, E.C., Njoya, O., Mballa, E., Nsangou, M.F., Njapom, C., Moukouri Nyolo, E., et al. (1991) Contribution of the Endoscopy in the Digestive Pathology Low in Cameroonian Environment. Analytical Study of 720 Exams. Médecine d Afrique Noire Electronique, 38, 835-839.

[17] Assi, C., Lohouès-Kouacou, M.J., Allah-Kouadio, E., Njossu, C.J., Okon, A.J.-B., Doffou, S., et al. (2012) Appropriateness of Colonoscopy in Cocody Teaching Hospital Center in 2010: A Prospective Study Using Criteria Established by the European Panel on the Appropriateness of Gastrointestinal Endoscopy (EPAGE). Open Journal of Gastroenterology, 2, 193. https://doi.org/10.4236/ojgas.2012.24039

[18] Endoscopie Colo-Rectale|SFED. http://www.sfed.org/professionnels/recommandations-et-autres-fiches/les-recomm 
andations/endoscopie-colo-rectale

[19] Lieberman, D.A., Williams, J.L., Holub, J.L., Morris, C.D., Logan, J.R., Eisen, G.M., et al. (2014) Colonoscopy Utilization and Outcomes 2000 to 2011. Gastrointestinal Endoscopy, 80, 133-143. https://doi.org/10.1016/j.gie.2014.01.014 